\title{
Participant Relationship and Code Choice in Communication: A Case of the University Community of Cape Coast, Ghana
}

\author{
Richard T. Torto \\ Department of Communication Studies, University of Cape Coast, Cape Coast, Ghana \\ Email: rchrdtorto@yahoo.co.uk
}

\begin{abstract}
The current study focused on the effect of interpersonal relationship on code choice in discourse situations in the university community of Cape Coast. The study also looked at the nature of the linguistic situation and the kinds of code choice in the university. It revealed that the university community of Cape Coast is multilingual and the kinds of code choice are: unmixed codes, code mixing and code switching. The research target population comprised: students, lecturers and the non-academic staff. The present study employed a sociolinguistic approach and it was conducted within the framework of ethnography of speaking and sociology of language. The study also adopted the ethnographic research design and the instruments used for data collection were: observation, questionnaire and interview. The findings of the research revealed that the interpersonal relationship between participants in discourse defined by age, sex, rank, level of education and ethnicity affected code choice.
\end{abstract}

Index Terms - participant relationship, code choice, sociolinguistics, multilingualism, communication

\section{INTRODUCTION}

Communication theory that emphasizes message content to the neglect of relational factors is simply not practical. Real-life interpersonal communication is often unpredictable and it always involves more than just the speaker's action. This realization has led some observers to propose an interactive model for interpersonal communication (Griffin, 2000). Like the game of charades, interpersonal communication is a mutual, ongoing process using verbal and nonverbal messages with another person to create and alter the images in both of our minds. According to Blumer (1969) meaning is negotiated through the use of language and out of the social interaction that people have with each other. It is only by talking with others that we come to ascribe that meaning and develop a universe of discourse. Mead (1934) claims that the most human and humanizing activity that people can engage in is talking to each other. A group of people living and working together in close proximity enforced by an institution like the university have to interact. Language is the means of communicating information and it is also the channel of establishing and maintaining relationship with other people (Trudgil, 1983). Communication in a social context patterns according to particular roles within a society defined by sex, age, social status, occupation, level of education, rural or urban residence and other features of social organisation. The University of Cape Coast where the current research was conducted is a multilingual community. Students and workers are drawn from the heterogeneous ethnic regions of Ghana. Due to the multilingual nature of the community, the subjects are normally faced with the problem of code choice. Wardhaugh (1986) defines "code" as a language or a variety of a language employed for communication in discourse situations. Crystal (1985) views the term code as any system of communication involving language. This means that when two or more individuals communicate with each other in speaking, for example, we can name the system of communication that they employ a code. In the present study, the researcher concerned himself with whole languages that are spoken in the university of Cape Coast. The concept of code in the current work means a language.

\section{REVIEW OF LITERATURE}

In this section, the researcher places the current study in the context of work done by other investigators with the view of showing how the present study is both similar and different from previous ones. The review covers both studies conducted in non-Ghanaian and Ghanaian contexts.

Parasher (1980) is a study on language choice among three-hundred-and-fifty educated people in two cities in the southern part of India. Parasher attempted to determine people's language use in domains in the sense of Fishman (1965, 1968). According to Fishman, there are certain institutional contexts called domains, in which a particular language variety is more likely to be appropriate than another. In the field of domains, certain situations are more formal than others. The language used in the family domain is the low one, whereas the language employed in more formal domains like education is high. Parasher (1980) found out about language use in seven domains: family, friendship, neighbourhood, transactions, education, government and employment. The respondents were instructed to state on the 
questionnaire administered which language among five languages (English, Mother tongue, the regional language, Hindi and other languages) they would use in each situation. From Parasher's study mother tongue dominated the family domain. English scored high in the education, government and employment domains. It also appeared strong in the friendship and neighbourhood domains and this was due to the fact that the educated Indians in the Southern part of India, where the research was conducted and where English tends to be favoured, do not share a common mother tongue with their colleagues.

Rubin (1968) presents a description of the bilingual situation that exists in Paraguay. According to him, two languages are employed for communication in this country; Spanish and Guarani. The former is the official language of government, business transactions, and the medium of education. It is used on formal occasions and conversations with strangers who are properly dressed. On the other hand, Guarani is used in informal discourse with friends, servants and strangers who are poorly dressed, and on most casual occasions. It is spoken more in the countryside than in the cities and towns. Guarani is employed by males in the upper classes as a sign of friendship. However, upper-class females prefer Spanish in informal interactions. Male Paraguayans may converse in Guarani at the initial part of a drinking session but switch to Spanish as they feel the influence of alcohol, the reason being that Spanish is the language of power. Paraguayans choose to converse in Guarani outside Paraguay among South-American Spanish-speaking people. This is an indication that Guarani is the language of solidarity. In Paraguay, Spanish is socially preferred. It is the language people choose when addressing superiors. The choice between Spanish and Guarani therefore depends on setting (City or Country), formality, sex, status, intimacy, seriousness, type of activity and situation. Fishman (1971) describes the language situation in Paraguay as diglossic; with Spanish as the 'high' variety and Guarani as the 'low'.

Forson (1968) is a description of the sociolinguistic situation in Ghana, with a focus on Akan- English bilingualism. According to Forson, Akan- English bilinguals can normally be said to have at least three languages to choose from: Akan, English and Akan mixed with English words, phrases, clauses and sentences. Forson points out that the situations where even the most highly educated Akans use or find themselves forced to employ 'unmixed' Akan include: when talking to illiterate Akan relations and acquaintances, when participating in a traditional ritualistic performance like libation, dirges and worship, when addressing an Akan community, when presenting folktales or riddles at a gathering which is predominantly Akan, when participating in radio or TV programmes in Akan and when bargaining with uneducated Akan traders. Some of the instances Forson cites when the Akan- English bilinguals use English are when in the company of educated non-Akans, when speaking to a gathering of educated people, when teaching in a classroom setting and for official or formal interactions. He reports that the Akan-English bilinguals mix the two languages when communicating in the environment of other Akan- English bilinguals. In the instances of mixing Forson reveals that it is Akan, which is mixed with various items of English and not the other way. It is also Forson's view that the quantity of English elements in the speech of the Akan- English bilingual depends on his knowledge of English and that in an informal discourse, mixing Akan with English depends on the educational backgrounds of the participants. He establishes that mixing occurs in all free discussions and other informal discourses, irrespective of the difference in social status of the interlocutors. Forson concludes that mixing is part of the linguistic life of most Ghanaians.

Forson (1979) reports that code-switching is the product of bilingualism or multilingualism and in it the participants share the same language in contact. Forson's work establishes that the Akan-English bilingual is equipped with three tongues; Akan, English and Akan-English code-switching. According to him these tongues complement one another in offering the bilingual three distinct language choices for separate categories of language use. Forson's idea of a third tongue is also the view of Wardhaugh (1986) and Owusu-Ansah (1992). Wardhaugh refers to Forson's third tongue as third code and Owusu-Ansah describes it as 'a contact variety'. Forson points out that the sociolinguistic factors which characterise normal code-switching are that there should be at least two tongues of which the non-native should be socially more prestigious than the local variety, the participants should be bilingual in the languages involved in the code-switching, the subject matter should not be typically indigenous and the discourse should be informal, unprepared and spoken. Forson (1979) also reveals that the participants in normal Akan-English code-switching consider themselves to be communicating in Akan. The discourse usually starts in Akan and as it progresses the interlocutors freely employ English items of varying lengths. However, if a subject matter is not easily communicated in English, it does not attract code-switching. Discourses involving topics that come under politics, academic subjects, international sports are usually in English because they are difficult to discuss or describe in monolingual Akan. Therefore, any discussion of these in Akan turns into code-switching.

Owusus- Ansah (1992) is an attempt at finding out how English is employed by speech communities that have other indigenous languages as their predominant means of communication. In his work, Owusu-Ansah investigates the differences between Ghanaian English and native varieties of English. He focuses on interpersonal relationships as one of the prominent areas of contextual differences in the Ghanaian university students' English. Owusu-Ansah (1992) also looks at language choice. It shows that depending on the level of formality, three possible code choices exist in Ghana. These comprise unmixed Ghanaian languages, mixed English-Ghanaian languages and unmixed English. The two unmixed languages are used in highly formal situations while mixed varieties are chosen as the level of formality falls.

It is worth noting that the investigations conducted by other researchers are similar to the present study in the domain of code choice. Another area of similarity is that the current research and the literature reviewed adopt a sociolinguistic approach. Aspects of Owusu-Ansah (1992) for instance, are based on interpersonal relationship and a framework of 
ethnography of speaking which the present work also deals with. The current study is different from other related works in the sense that it is a research into interpersonal relationship and code choice in discourse situations. The sample frame for the present work comprises: students, lecturers and non-academic workers of the University of Cape Coast. The other studies on code choice have different sources of data and informants. For example Parasher (1980) is conducted among educated Indians in the southern part of Indian; Greenfield's (1972) is carried out among Puerto Ricans in New York City, Blom and Gumperz (1972) in the Norwegian village of Hemnesberget and Rubin (1968) in Paraguay. Owusu-Ansah's (1992) data for example were gathered from university students in Ghana. His study is based on both the spoken and written mediums of communication but the present research is confined to the spoken. The significance of this approach is that the current study concerns itself with code choice and this linguistic concept applies more to the spoken medium of communication than the written. Forson $(1968,1979)$ are to some extent limited in their attempt at depicting the linguistic situation in the sense that Ghana is multilingual but his works have been given a bilingual approach. The present study is looking at code choice between English and the other Ghanaian languages and not just Akan.

\section{Methodology}

\section{A. Research Design}

The research design employed in the present study is an integrated method involving both qualitative and quantitative approaches (Creswell, 2003). Qualitative research design offers the researcher the chance to study naturally occurring linguistic phenomena. With this design, descriptions of observations are expressed largely in non-numerical terms. Nonetheless, quantitative research uses specific measurement of variables. This provides the connection between empirical observation and mathematical expression of quantitative relationships. The quantitative method adopted in the current research involves simple frequency and means and this helped to identify responses to the variables of interpersonal relationship under study.

\section{B. Population}

The research population comprised: students, lecturers and non-academic staff of the University of Cape Coast. The university community of Cape Coast consists of people from the diverse ethnic regions in Ghana. As a result, many different languages co-exist and individuals speak more than one language. The research population is heterogeneous and multilingual.

\section{Sampling}

The present study employed the cluster and stratification sampling designs. The total sample frame for the research was two hundred and thirty (230). Two hundred (200) responded to questionnaire and thirty (30) were interviewed. Out of the total number of two hundred (200) respondents to questionnaire, one hundred and twenty five (125) were students and seventy-five (75) were workers. These classifications in the sampling were influenced by the available statistics of the university, which show that students population is more than the workers. The thirty informants in the 230 sampling frame who were interviewed comprised: ten students, ten lecturers and ten non-academic staff.

\section{Research Instruments}

The instruments used for data collection were observation, questionnaire and interview.

Observation was the main research instrument used in the present study. It provided an empirical basis for capturing language used in its social context. The methods of observation used were participant and non-participant. The investigator interacted with the research target population and observed closely the use of language in various contexts of situation. The questionnaire helped the investigator solicit information for both demographic and sociolinguistic data of the research. In all, about two hundred and thirty (230) questionnaire handouts were administered directly to the informants. The researcher had a checklist in place to ensure that respondents provided accurate information. A number of follow-ups were also done in order to retrieve all the questionnaire handouts administered. The interview was conducted with the aid of a schedule. The researcher established rapport with the interviewees. Appointments were booked with some of the informants while others agreed to be interviewed immediately. The interview was carried out on one - on - one basis. It was conducted at a time and place convenient for the informants. The interview proceeded smoothly without personal contributions from the interviewer.

\section{ANALYSIS AND DisCUSSION}

This section of the study deals with the analysis of data and discussion of the research findings. A preliminary analysis was conducted to obtain quantitative information on the responses of informants. The discussion was done with reference to the objectives of the study. 
TABLE 1:

LANGUAGES SPOKEN BY RESPONDENTS

\begin{tabular}{|l|l|}
\hline Languages & Number of respondents \\
\hline English & 200 \\
Ghanaian languages & 200 \\
Pidgin & 54 \\
Foreign languages & 8 \\
\hline
\end{tabular}

From Table1 it can be observed that all the respondents spoke a Ghanaian language and English. The Ghanaian languages spoken in the university were: Akan, (Nzema, Guan, Ahanta, Efutu) Ga, Ewe, Dagbani, Dagaare. There were 8 foreign languages (German, Spanish, Amharic, Italian and French) spoken by lecturers who might have travelled for further studies to the countries in which these languages were spoken. Pidgin was spoken by 54 respondents. The investigator found out who spoke Pidgin, to whom and when and to what end. Pidgin was employed for communication in informal discourse situations. The use of English, Ghanaian language and Pidgin makes the university a multilingual community. There were individuals who could speak English and their mother tongues only. Others could speak about three to four languages.

TABLE 2:

ETHNIC DIFFERENCES AND CODE CHOICE

\begin{tabular}{|l|l|l|}
\hline ETHNIC BACKGROUND & FREQUENCY & PERCENTAGE (\%) \\
\hline Akan & 133 & 66.5 \\
Ga & 14 & 7 \\
Ewe & 28 & 14 \\
Nzema & 3 & 1.5 \\
Dagbani & 4 & 2 \\
Frafra & - & - \\
Kasem & - & - \\
Konkonba & - & - \\
Gonja & 1 & 0.5 \\
Dagaare & 10 & 5 \\
Wala & - & - \\
Others & 7 & 3.5 \\
\hline TOTAL & $\mathbf{2 0 0}$ & $\mathbf{1 0 0}$ \\
\hline
\end{tabular}

Table 2 shows the ethnic background of respondents. From the Table $133(66.5 \%)$ respondents out of the total number of 200 informants were Akans. The Ewes were 28 (14\%) followed by the Ga ethnic group with 14 (7\%) respondents. In addition to Nzema, Dagbani, Gonja and Dagaare, other ethnic groups that were represented in the research sample frame were 7 (3.5\%). These were Nankani, Guan, Ikposo, Bissa, Dangme, Efutu and Krobo. From the above table, Frafra, Kasem and Konkonba were not represented in the present research though they are also ethnic groups in Ghana. The ethnicity of respondents depicts the multilingual nature of the research target population. The university community is made up of people from different ethnic backgrounds. As a result many different indigenous languages are spoken in the university. Most of the informantns could speak two or more of the Ghanaian Languages. On the other hand, in monolingual situations, a Ga and an Ewe could not communicate in view of the fact that the two languages are mutually unintelligible. The English Language, however, cuts across ethnic barriers; it functions as lingua franca. English facilitated communication between interlocutors of different ethnic backgrounds. Among the Ghanaian languages, Akan had the highest number of speakers. In fact, virtually everybody in the university community can speak some form of Akan. Speakers of other Ghanaian languages can speak it in addition to their mother tongues. The position of Akan vis-a-vis the other Ghanaian languages makes the former a potential national language. Almost all the informants spoke English and their mother tongues. There were therefore Akan-English, Ewe-English, Dagbani-English, Dagaare-English bilinguals and so on. There were also individuals who could speak two or three Ghanaian languages in addition to the English Language. There were Akan-Ga-English, Ga-Ewe-English, Akan-Dagaare-English, Akan-GaEwe-English, Dagbani-Frafra-Dagaare-English multilinguals and so on.

Mixing the Ghanaian languages with English was very common in the university. Most of the informants explained that mixing the local language with English occurred because certain registers in English did not exist in the Ghanaian language and this made code mixing somehow unavoidable. Furthermore, many respondents were not very proficient in the local languages and this also brought about mixing. The research revealed that in mixing it was the Ghanaian language that was mixed with English words, phrases and other expressions but not the other way round. Switching from English to the Ghanaian language or vice-versa occurred in most situations in the university. For instance, the presence of a third person in a dialogue in English triggered off a situation of code switching when this new person who joined the conversation switched to a Ghana language common to one of the interlocutors.

TABLE 3:

SEX AND CODE CHOICE

\begin{tabular}{|l|l|l|}
\hline Sex & Frequency & Percentage (\%) \\
\hline Male & 112 & 56 \\
Female & 88 & 44 \\
\hline Total & $\mathbf{2 0 0}$ & $\mathbf{1 0 0}$ \\
\hline
\end{tabular}


Table 3 describes the distribution of responses according to sex. Out of a total of 200 informants, 56\% (112) were males while $44 \%$ (88) were females. The dominance of male in terms of number represents a reflection of the available statistics of the university which depicts the male population out numbering the female. The way that sex affected code choice was that in the university community majority of females spoke English or the Ghanaian languages but not Pidgin. The majority of the males on the other hand spoke Pidgin in almost all informal discourses. Male student Pidgin Speakers spoke Pidgin to their male colleague students but not to lecturers. The majority of the male students did not speak pidgin to female students. Female pidgin speakers spoke it with males but not females. The bulk of the latter did not employ pidgin in their speeches because they had attached some stigma to it. The females regarded pidgin as an inferior language that was associated with rouges and illiterates. Variation according to the sex of participants in discourse has been the subject of many recent researches. The general inference from dialect surveys is that female speakers tend to use more prestigious forms than male speakers with the same general social background (Yule, 1996).

TABLE 4:

AGE AND CODE CHOICE

\begin{tabular}{|l|l|l|}
\hline Age Range & Frequency & Percentage (\%) \\
\hline $14-19$ & 3 & 1.5 \\
$20-24$ & 46 & 23 \\
$25-29$ & 25 & 12.5 \\
$30-34$ & 26 & 13 \\
$35-39$ & 32 & 16 \\
$40-44$ & 23 & 11.5 \\
$45-49$ & 22 & 11 \\
$50-54$ & 10 & 5 \\
$55-59$ & 5 & 2.5 \\
$60-$-plus & 8 & 4 \\
\hline Total & $\mathbf{2 0 0}$ & $\mathbf{1 0 0}$ \\
\hline
\end{tabular}

Table 4 presents the age distribution of respondents. From the table, 46 (23\%) respondents were in the range of 20 to24 years. This can be attributed to the fact that most of the respondents were students and majority of them are younger than lecturers and the non-academic workers. The age range 14 to 19 had the least number of respondents and these were also students. 8 (4\%) respondents- 7 lecturers and 1 non- academic staff- fell within the age range 60 years and above. The age distribution of the University of Cape Coast ranges between 19 and 60 years and above. The age differences between respondents affected their choice of code. It was discovered that the choice of Pidgin was associated mostly with respondents between the age range 19 and 34 years. Respondents between the ages of 35 and 60 did not speak Pidgin.

Student pidgin speakers did not speak it with mature students or with lecturers. Student pidgin-speakers employed pidgin in discourses involving those of their age group. Students who spoke pidgin perceived mature students as elderly people who would not be enthused to speak pidgin. Students would not speak pidgin with lecturers, since the former regarded the latter as elderly and with higher academic qualifications and status. The relationship between students and lecturers could be described as formal. Most lecturers on their part did not speak pidgin to students because according to them, pidgin is a sub-standard language and it did not befit their status. The few lecturers who spoke pidgin said they were not too proficient in it and they spoke it to some labourers but not to other lecturers or to students.

TABLE 5:

ACADEMIC QUALIFICATION AND CODE CHOICE

\begin{tabular}{|l|l|l|}
\hline ACADEMIC QUALIFICATION & FREQUENCY & PERCENTAGE (\%) \\
\hline Middle School Leaving Certificate & 10 & 5 \\
General Certificate of Education (Ordinary level) & 12 & 6 \\
General Certificate of Education (Advance level) & 32 & 16 \\
Senior Secondary School Certificate & 21 & 10.5 \\
Teacher Training College Certificate & - & - \\
Specialist or Diploma & 45 & 22.5 \\
First Degree & 49 & 24.5 \\
Masters Degree & 18 & 9 \\
Doctorate Degree & 12 & 6 \\
Others & 1 & 0.5 \\
\hline Total & $\mathbf{2 0 0}$ & $\mathbf{1 0 0}$ \\
\hline
\end{tabular}

According to Table 5, 49 (24.5\%) respondents possessed the first degree while 45 (22.5\%) were diplomates. There were $32(16 \%)$ who had the General Certificate of Education (Advanced level). Senior Secondary School Certificate holders were 21(10.5\%). There were $12(6 \%)$ with the General Certificate of Education (Ordinary level). Middle School Leaving Certificate holders were $10(5 \%)$. Respondents with Masters Degree were 18(9\%) and these were lecturers and non-academic workers. The students selected for the current investigation were undergraduates and post graduate masters students. 12(6\%) respondents have their Doctorate Degrees; this group was made up of lecturers. There was no respondent with the Teacher Training College Certificate. However, there was $1(0.5 \%)$ respondent with the City and Guilds London Certificate. This was a member of the non-academic staff. The above analysis shows that the sample 
frame of the current research is made up of people who have received formal education and for that matter were literates. Every subject could therefore speak English since it is an integral part of formal education in Ghana.

TABLE 6:

RANK AND CODE CHOICE

\begin{tabular}{|l|l|l|}
\hline Rank & Frequency & Percentage (\%) \\
\hline Senior members & 30 & 15 \\
Senior staff & 16 & 8 \\
Post graduate students & 40 & 20 \\
Undergraduate students & 85 & 42.5 \\
Junior staff & 29 & 14.5 \\
Others & - & - \\
\hline Total & $\mathbf{2 0 0}$ & $\mathbf{1 0 0}$ \\
\hline
\end{tabular}

Table 6 presents the rank of respondents. There were $85(42.5 \%)$ undergraduates and $40(20 \%)$ post graduate masters students. Senior members are workers of the university with higher degrees and these were $30(15 \%)$. While $16(8 \%)$ of the respondents were senior staff $29(14.5 \%)$ were junior staff. The ranks of informants were connected to their academic qualifications. Rank to a large extent brought about social differentiation in the university. According to the findings of the present study, senior members of the university did not speak Pidgin.

The rank of respondents were determined by their levels of education. The rank of informants showed their positions on the social hierarchy of the university. Academic qualification and rank brought about social differentiation and this established distinction in relationships. The ranking system of the workers of the university is hierarchical. It comprises senior members, senior staff and junior staff. The senior members comprise lecturers and the non-academic staff who have higher degrees like Masters, Doctorates and other qualifications from Professional bodies. The senior staff have first degrees or their equivalents as their basic qualification. This group may have additional qualifications in their various fields of specializations. The minimum academic qualification of the junior staff is the General certificate of Education Ordinary or Advanced Level or the Senior Secondary School Certificate. It is worth nothing that the illiterate labourers who do menial jobs have no rank because they do not possess any academic qualification.

Lecturers employed either Ghanaian language or English in most informal discourses like conversations and discussions. In discourse situations in which the local language was chosen, a lot of code-mixing occurred. The Ghanaian languages were mixed with English elements. In many instances, if the subject of the discourse was academic, lecturers spoke English in the communication process. However, a change in the discourse subject to a social issue brought about a switch to the Ghanaian language. The cordial relationship between lecturers shrouded the existing distinctions between them.

Among the non-academic workers of the university, English was the official language used for communication. The Ghanaian languages were chosen for communication during informal interactions. One would expect that an assistant registrar would speak English when discussing an issue with the deputy registrar or the registrar but in the informal discourses the Ghanaian languages were employed except in a formal discourse like a meeting that English was strictly used. In the offices of the various departments of the university administration, the Ghanaian languages, especially Akan was spoken. Mixing the Ghanaian languages with English was characteristic of many a respondent. A switch from the local language to English or vice versa was also realized. In situations where there was no common Ghanaian language, English was chosen. Workers at the subordinate level like messengers or labourers were not proficient in English. It was observed that they always spoke Akan to their superiors. The senior members and senior staff used the indigenous languages in communicating with the junior staff when they share similar ethnic background or when a superior is on familiar terms with the subordinates.

\section{CONCLUSION AND IMPLICATIONS}

In this study, the investigator concerned himself with participant relationship in discourse and its effect on code choice. In this section, the main findings and implications of the research are presented.

The study revealed that the relationship between participants in communication defined by age, sex, rank, level of education and ethnicity affected code choice. The research also showed that the University of Cape Coast is a multilingual community and the kinds of code choice that exist are: unmixed codes, code mixing and code switching. The current study has three significant implications. The first implication is that the present research depicts the social differentiation in the University of Cape Coast; It establishes the social stratification of the subjects. The secondly, the findings of this study may be useful to researches in the area of sociology or anthropology. The study contributes to the sociolinguistic study of the University community by establishing the kinds of code choice that occur in communication. Finally, the findings of the research shows that the University of Cape Coast is a microcosm of the multilingual situation in Ghana.

\section{REFERENCES}

[1] Blom, J. P. and Gumperz, J. J. (1972). 'Social meaning in linguistic structures: code switching in Norway'. In Gumperz and Hymes 1972: 407-34. 
[2] Blumer, H. (1969). Symbolic Interactionism. Prentice-Hall, Englewood Cliffs, N. J., pp.53-56.

[3] Creswell, J. W. (2003). Research design: Qualitative, quantitative, and mixed method approaches. CA: Sage Publications.

[4] Crystal, D. (1985). A dictionary of linguistics and phonetics. UK: Basil Blackwell Ltd.

[5] Fishman, J.A. (1965). 'Who speaks what language to whom and when? Linguistics 2:67-8.

[6] Fishman, J.A. (1968). 'Sociolinguistic perspective on the study of bilingualism.' Linguistics, 39: 21 - 49.

[7] Fishman, J. A.( ed.), (1968). Readings in the Sociology of language. Netherlands: Mouton and Co. Publishers.

[8] Fishman J. A. (ed). (1971). Advances in the sociology of language. Netherlands: Mouton and Co. Publishers.

[9] Forson, B. (1968). 'Description of language situations classified in a corpus representing a bilingual register range (Akan varieties and English).' Unpublished M.A. Thesis, Legon.

[10] Forson, B. (1979). 'Code switching in Akan - English bilingualism'. Unpublished Ph D. Thesis, University of California, Los Angeles.

[11] Greenfield, L. (1972). 'Situational measures of normative language views in relation to person, place and topic among Puerto Rican bilinguals.' In Fishman 1972: 17-35.

[12] Griffin E. (2000). A First Look at Communication Theory. USA: McGraw-Hill.

[13] Mead G.H. (1934). Mind, Self and Society. Chicago: Chicago University.

[14] Owusu - Ansah, L. (1992). 'Variation according to context in a second language: A study into the effect of formality on the English used by Ghanaian University Students.' Unpublished $\mathrm{PhD}$ thesis, the University of Edinburgh.

[15] Parasher, S.N. (1980). Mother-tongue-English Diaglossia: A case study of educated India bilinguals' language use. Anthropological Linguistics 22 (4): 151-68.

[16] Rubin, J. (1968). National Bilingualism in Paraguay. The Hague: Mouton. Excerpted in Pride and Holmes (1972).

[17] Trudgill, P. (1974). Sociolinguistics: An introduction to language and society. England: Penguin Books Ltd.

[18] Wardhaugh, R. (1986). An introduction to sociolinguistics. UK: Blackwell Publishers.

[19] Yule, G. (1996). The study of language. Great Britain: Cambridge University.

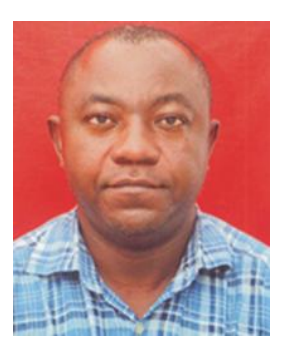

Richard T. Torto was born at Accra, Ghana in the year 1965. Torto attended Osu Maa-Aba Primary and Air Borne Force Complex, continued his education at St. Charles Secondary school from 1980 to 1985 and Tamale Secondary School from 1985 to 1987. Torto entered the University of Cape Coast in 1989 for the Bachelor of Arts Degree in English and in the year 2000, obtained the Master of Philosophy Degree in English from the same university.

He has to his credit well over twenty years teaching experience. He taught at Wesley Girls High School and Ghana National College. He is currently a lecturer at the Department of Communication Studies at the University of Cape Coast, Ghana. He has published a number of literary works, some of which are General Knowledge of Literature: Introduction to literary devices, terms and concepts (2005, Nyakod Publishers, Cape Coast, Ghana) and Communication in the world of fantasy: A case of Inez Haynes Gillmore's Angel Island (Language in India, 12(2) 2012 pp. 687-711). His research interests are in Communication Studies, Literature and Sociolinguistics.

Mr Torto is the moderator of the communicative skills programme of affiliated university colleges to the University of Cape Coast. $\mathrm{He}$ is a member of the supervisory board in charge of colleges of education in Ghana and also a member of the Faculty of Arts Examination Board of the University of Cape Coast. 